\title{
Application of Simultaneous Morcellation in situ in Laparoscopic Myomectomy of Larger Uterine Leiomyomas
}

\author{
Peihai Zhang ${ }^{a}$ Kun Song ${ }^{a}$ Li Li $^{a} \quad K^{2}$ Kazunori Yukuwa ${ }^{b}$ Beihua Kong ${ }^{a}$ \\ a Department of Gynecology, Qilu Hospital of Shandong University, Jinan, China; ${ }^{b}$ School of Medicine, \\ Wakayama Medical University, Wakayama, Japan
}

\section{Key Words}

Uterine leiomyoma - Laparoscopic myomectomy •

Simultaneous morcellation in situ

\begin{abstract}
Objectives: To describe the efficiency, blood loss, operating time and mean hospital stay of enucleation of a large myoma by 'simultaneous morcellation in situ' (SMI) in laparoscopic myomectomy (LM). Patients and Methods: Twenty-six patients with leiomyomas $>9 \mathrm{~cm}$ in diameter were treated using LM and SMI from January 2006 to December 2009. Patient characteristics and operative data were collected and analyzed. Results: The average operating time was $106.4 \pm$ $38.5 \mathrm{~min}$ (range 50-175 $\mathrm{min}$ ). The average blood loss was $278.2 \pm 164.6 \mathrm{ml}$ (range $50-800 \mathrm{ml}$ ). There was no other complication, and no patient underwent conversion to laparotomy. The average postoperative hospital stay was $5.4 \pm$ 0.2 days (range $5-7$ days). Conclusion: Our study confirmed that SMI is an efficient and safe way to remove large uterine myomas $(>9 \mathrm{~cm})$ during LM. $\quad$ Copyright $\odot 2011$ S. Karger AG, Basel
\end{abstract}

\begin{tabular}{ll}
\hline KARGER & ( ) 2011 S. Karger AG, Basel \\
Fax +41 61306 $1234-7571 / 11 / 0205-0455 \$ 38.00 / 0$ \\
$\begin{array}{l}\text { E-Mail karger@karger.ch } \\
\text { www.karger.com }\end{array}$ & $\begin{array}{l}\text { Accessible online at: } \\
\text { www.karger.com/mpp }\end{array}$
\end{tabular}

\section{Introduction}

It is well-known that laparoscopic myomectomy (LM) has many advantages over laparotomy including shorter hospital stay, faster convalescence, less adhesion formation, and less postoperative pain [1]. However, LM also has disadvantages such as longer operating time and possibly higher blood loss. Especially when treating large leiomyomas, LM could result in a shortage of operating room availability. These circumstances limit the application of LM. With the improvements in instruments and operative techniques, larger leiomyomas can now be removed laparoscopically [2-4]. We have successfully used laparoscopic simultaneous morcellation in situ (SMI) [5] to remove uterine leiomyomas with a diameter $>9 \mathrm{~cm}$ and obtained good clinical results.

\section{Patients and Methods}

Patients

From January 2006 to December 2009, 26 patients with leiomyomas $>9 \mathrm{~cm}$ in diameter were treated by LM and SMI. The average age of these patients was $37 \pm 4$ years (range 23-43 years). Twenty-three patients had given birth but desired to preserve 
Table 1. Characteristics of patients with large leiomyomas $(n=26)$

\begin{tabular}{lcc}
\hline & Value & $\begin{array}{c}\text { Average/ } \\
\text { percentage }\end{array}$ \\
\hline Dominant myoma diameter, cm & $9-20$ & $13.6 \pm 3.1$ \\
Leiomyomas & $1-5$ & $2.6 \pm 1.8$ \\
Leiomyoma weight, $g$ & $225-950$ & $474.5 \pm 154.1$ \\
Operating time, min & $50-175$ & $106.4 \pm 38.5$ \\
Type of dominant myoma & & \\
$\quad$ Intramural & 19 & $73.1 \%$ \\
$\quad$ Subserosal & 7 & $26.9 \%$ \\
$\quad$ Submucous & 0 & 0 \\
Location of dominant myoma & & \\
$\quad$ Anterior & 12 & $46.1 \%$ \\
$\quad$ Fundus & 6 & $23.1 \%$ \\
$\quad$ Posterior & 8 & $30.8 \%$ \\
Total blood loss, ml & $50-800$ & $178.2 \pm 164.6$ \\
Blood transfusions & 4 & $15.4 \%$ \\
Hospital stay, days & $5-7$ & $5.4 \pm 0.2$ \\
\hline
\end{tabular}
mined by B-type ultrasonography, while in the remaining 2 patients magnetic resonance imaging was used. Three patients had a history of abdominal surgery; 2 had received cesarean section, and 1 had had appendectomy. Gynecological examinations were performed preoperatively to exclude genital tract inflammation. Curettage or hysteroscopic examination was performed to exclude endometrial malignancy and submucous leiomyoma. Cervical Thinprep Cytology Test (TCT) was performed to exclude cervical lesions.

\section{Operative Procedure}

The patients placed in the dorsosacral position underwent single-lumen endotracheal tube anesthesia. A Foley catheter for continuous urinary draining and a uterine elevator were placed through the cervix. A four-trocar method was used. One $10-\mathrm{mm}$ trocar was placed above the umbilicus. A 5-mm trocar was placed on the left side of the lower abdomen and a $15-\mathrm{mm}$ trocar was placed $3 \mathrm{~cm}$ above and $3 \mathrm{~cm}$ to the right of the pubic symphysis. Another 5-mm trocar was placed on the right side of the abdomen, which is $4 \mathrm{~cm}$ above McBurney's point. It was about $8 \mathrm{~cm}$ from the $15-\mathrm{mm}$ trocar. Abdominal pressure was maintained at $14 \mathrm{~mm} \mathrm{Hg}$ with carbon dioxide. A solution of $6 \mathrm{U}$ vasopressin in $200 \mathrm{ml}$ saline was injected at several points into the normal myometrium between the leiomyoma and the uterine serosa to enable uterine contraction so as to avoid heavy bleeding from occurring. A $15-\mathrm{mm}$ rotation resection machine was placed through the 15$\mathrm{mm}$ trocar, and a large clamp was used to grasp the most superficial portion of the leiomyoma and the pseudocapsule of the leiomyoma was incised. At this time, the protrusion of the leiomyoma was clearly seen. The leiomyoma and excess pseudocapsule were further morcellated to decrease its volume, while carefully observing the leiomyoma and surrounding tissues. The morcellation procedure was stopped when the normal myometrium was approached. After SMI was done, the main body of the myoma was morcellated to reduce myoma volume. There was still a small portion of the myoma left in the uterine body. The remaining piece of myoma was enucleated. Monopolar cautery or blunt dissection was used to remove the leiomyoma and separate the membrane. Bipolar electrocoagulation of the cavity was used for those without fertility requirements. The myometrial edge was approximated by interrupted intracorporeal sutures in one or two layers using No. 1 absorbable sutures. When hemostasis was complete, the remaining leiomyoma was morcellated and removed for pathological examination. The abdomen was irrigated, and pressure was released, and the antiadhesion membrane was placed. A drainage tube was inserted if necessary.

\section{Data Recorded}

The diameter of the dominant leiomyoma, the number and weight of leiomyomas, operating time (from the insertion of the first trocar to the completion of wound closure), the length of hospital stay, complications, blood loss, blood transfusions, conversion to laparotomy, or requirement of laparotomy in the postoperative period were recorded.

\section{Results}

In these 26 cases, the largest leiomyoma was $20 \mathrm{~cm}$ in diameter. Five patients had leiomyomas $>14 \mathrm{~cm}$, and 21 patients had leiomyomas 9-14 cm. Myoma characteristics and operative data are presented in table 1. A total of 44 leiomyomas were removed in the 26 patients. The largest number of leiomyomas removed in a single patient was 5 , and the largest one among all patients weighed $950 \mathrm{~g}$. The average operating time was $106.4 \pm 38.5 \mathrm{~min}$ (range 50-175 $\mathrm{min}$ ). The average blood loss was $278.2 \pm$ $164.6 \mathrm{ml}$ (range 50-800 ml). Four patients received a blood transfusion because blood loss exceeded $500 \mathrm{ml}$. There was no other serious complication, and no patient had to be treated by laparotomy. The average postoperative hospital stay was $5.4 \pm 0.2$ days (range 5-7 days).

As shown in figure 1, 21 patients had smaller myomas (diameter 9-14 cm); the operating time and total blood loss were both less than for the 5 patients with larger myomas (diameter $>14 \mathrm{~cm}$ ). Among the smaller myoma group, only 1 case (4.7\%) needed blood transfusion compared to 3 cases $(60 \%)$ in the bigger myoma group. However, there was no significant statistical difference in hospital stay between the two groups, as shown in table 2 .

\section{Discussion}

The most commonly encountered contraindications for LM are leiomyoma diameter $>10 \mathrm{~cm}$, more than 4 leiomyomas, leiomyoma located deep in the myometrium, 
Fig. 1. Operating time and intraoperative blood loss for the two patient groups based on myoma size.

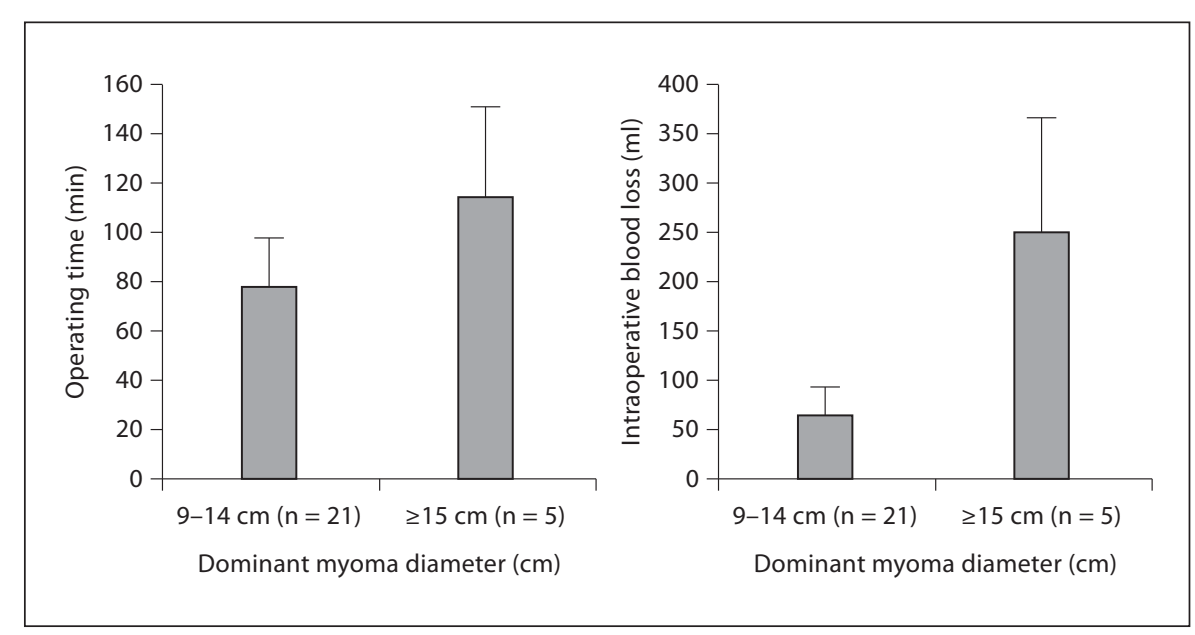

and cervical leiomyoma [6]. For patients with larger leiomyomas who wish to be treated by LM, researchers have improved the operative methods. Sinha et al. [7] reported a modified LM method in which morcellation was applied while the myoma was enucleated partially but still attached to the uterus. In 2000 and 2001, they used this method to remove leiomyoma laparoscopically in those cases in which leiomyomas were $>7 \mathrm{~cm}$ in diameter, uterine volume was $>12$ weeks' pregnancy, and the number of leiomyomas with a diameter $>5 \mathrm{~cm}$ was more than 3 . They compared the results with traditional LM and found that there was no difference in leiomyoma weight, blood loss during surgery, and the length of hospital stay. This modified LM method greatly decreased the operating time (97.7 \pm 27.06 vs. $123 \pm 38.8 \mathrm{~min})$, which was almost the same as in our study (106.4 $\pm 38.5 \mathrm{~min})$. In 2008, Sinha et al. [8] reported on 505 uterine leiomyoma patients treated using this method. The average operating time was $60 \mathrm{~min}$ (range 30-270 $\mathrm{min}$ ) and average blood loss was $90 \mathrm{ml}$ (range $40-2,000 \mathrm{ml}$ ). They concluded that the size, number, and location of leiomyomas did not limit the application of LM when the laparoscopic surgeon providing LM was experienced. In our study both the average operating time $(106.4 \pm 38.5 \mathrm{~min})$ and the average blood loss $(178.2 \pm 164.6 \mathrm{ml})$ were larger than in the report by Sinha et al. [8]. That was probably because the size of leiomyomas in our study was much larger (13.6 \pm 3.1 vs. $5.86 \pm 3.30 \mathrm{~cm}$ ). Another important reason was that the group of Sinha et al. [8] was more experienced than us. They started this kind of surgery in 2000, which was 6 years earlier than us. Experience is quite essential for surgeons.

Simultaneous Morcellation in

Laparoscopic Myomectomy
Table 2. Operative data based on leiomyoma size

\begin{tabular}{lcll}
\hline $\begin{array}{l}\text { Dominant myoma } \\
\text { diameter, cm }\end{array}$ & $\begin{array}{l}9-14 \mathrm{~cm} \\
(\mathrm{n}=21)\end{array}$ & $\begin{array}{l}\geq 15 \mathrm{~cm} \\
(\mathrm{n}=5)\end{array}$ & $\begin{array}{l}\mathrm{p} \\
\text { value }\end{array}$ \\
\hline $\begin{array}{l}\text { Operating time, min } \\
\text { Intraoperative blood loss, } \mathrm{ml}\end{array}$ & $64 \pm 18.6$ & $113 \pm 36.5$ & $<0.01$ \\
$\begin{array}{l}\text { Blood transfusion, \% } \\
\text { Hospital stay, days }\end{array}$ & 4.7 & $646 \pm 122.6$ & $<0.01$ \\
& $4.8 \pm 1.2$ & $5.6 \pm 2.2$ & $>0.001$ \\
\hline
\end{tabular}

Torng et al. [5] modified the method of Sinha et al. [8] by doing morcellation directly on the uterine surface without prior enucleation and named the procedure 'simultaneous morcellation in situ' (SMI). They retrospectively analyzed the results of 174 patients who were treated by LM during 2003 and 2007. Traditional LM was used in the first 4 years and SMI was used in the 5th year. SMI provided a further 19-min reduction in the predicted operating time. They found that the size of the leiomyoma was the main factor that affected operating time, and the operating time was significantly shorter in the 5th year than in the first 4 years, suggesting that operative experience is a major factor influencing operating time. In 2010, Chen et al. [9] updated their research results. A total of 82 patients diagnosed with myoma or adenomyosis received SMI treatment. The mean myoma weight was $265 \pm$ $240 \mathrm{~g}$ and the mean operating time was $93 \pm 30 \mathrm{~min}$. In our study, the mean leiomyoma weight was $474.5 \pm$ $154.1 \mathrm{~g}$, and accordingly, the mean operating time was $106.4 \pm 38.5 \mathrm{~min}$, both being more than the values reported by Chen et al. [9]. All these results proved that operating time increased with myoma size.

Med Princ Pract 2011;20:455-458 
Our group started the SMI method in 2006 and focused on patients with leiomyoma $>9 \mathrm{~cm}$ who desired to preserve their uterus and wanted to be treated by LM. We have obtained very good results through these years. The average leiomyoma diameter was $13.6 \pm 3.1 \mathrm{~cm}$ (range $9-20 \mathrm{~cm}$ ) and the average leiomyoma weight was $474.5 \pm$ $154.1 \mathrm{~g}$ (range 225-950 g), which were both larger than in other reports [7-9]. As a result, the average operating time was $106.4 \pm 38.5 \mathrm{~min}$ (range 50-175 min), which was longer than in other reports. The operating time increased with myoma size. In view of the larger myoma size in our study, the operating time was still acceptable comparing to other reports [7-9]. Because the operating time was shorter, the average blood loss was $178.2 \pm$ $164.6 \mathrm{ml}$ (range $50-800 \mathrm{ml}$ ), which was also acceptable in surgery. Several articles introduced uterine artery ligation before morcellation to reduce bleeding. In our cases, this procedure was substituted by local vasopressin administration, which stimulates uterine contractions to avoid heavy bleeding. Vasopressin could be administered repeatedly if necessary. No serious bleeding happened in our cases. Because the myoma size in our cases was too large to expose the uterine artery and it was difficult to perform uterine artery ligation, local vasopressin administration was much easier to perform and did work effectively comparing to uterine artery ligation. On the other hand, whether uterine artery ligation could affect ovarian function or not is not clear yet.

The length of hospital stay was 5-7 days (average 5.4 \pm 0.2 days) in our study, which is longer than the 1-2 days in the USA and 2-3 days in Europe due to the difference in the medical system between China and the
USA or Europe. In China the community medical system has not yet been set up. Patients who are going to receive surgery have to be hospitalized first. All preoperative medical auxiliary examinations such as X-ray, ultrasonography and blood tests, etc., can only be performed after their hospitalization. These examinations take around 2 days in our hospital. For the same reason, patients have to stay long enough in hospital after the surgery until their body has recovered completely because there is no community clinic in China where they can be transferred. This is the reason why hospital stay is longer in our study. No serious complications have occurred in our cases, which is usually the reason for long hospital stays, and there is no significant statistical difference in the time of hospital stay between small myoma and big myoma groups as shown in table 2 .

\section{Conclusion}

Our study confirmed that SMI was an efficient and safe way to remove uterine large-size myoma $(>9 \mathrm{~cm})$. SMI helps to shorten the operating time and reduce blood loss significantly during LM.

\section{Acknowledgment}

This work was supported by grants from the National Natural Science Foundation of China (No. 30700897) and New Teacher Foundation in Ministry of Education (20090131120063) to Kun Song.

\section{References}

1 Hurst BS, Matthews ML, Marshburn PB: Laparoscopic myomectomy for symptomatic uterine myomas. Fertil Steril 2005;83:1-23.

$\checkmark 2$ Sinha R, Hegde A, Warty N, Patil N: Laparoscopic excision of very large myomas. J Am Assoc Gynecol Laparosc 2003;10:461-468.

3 Damiani A, Melgrati L, Marziali M, Sesti F, Piccione E: Laparoscopic myomectomy for very large myomas using an isobaric (gasless) technique. JSLS 2005;9:434-438.

4 Glasser MH: Minilaparotomy myomectomy: a minimally invasive alternative for the large fibroid uterus. J Minim Invasive Gynecol 2005; $12: 275-283$.
-5 Torng PL, Hwang JS, Huang SC, Chang WC, Chen SY, Chang DY, Hsu WC: Effect of simultaneous morcellation in situ on operative time during laparoscopic myomectomy. Hum Reprod 2008;23:2220-2226.

6 Tulandi T, al-Took S: Endoscopic myomectomy: laparoscopy and hysteroscopy. Obstet Gynecol Clin North Am 1999;26:135-148.

7 Sinha R, Hegde A, Warty N, Mahajan C: Laparoscopic myomectomy: enucleation of the myoma by morcellation while it is attached to the uterus. J Minim Invasive Gynecol 2005;12:284-289.
8 Sinha R, Hegde A, Mahajan C, Dubey N, Sundaram M: Laparoscopic myomectomy: do size, number, and location of the myomas form limiting factors for laparoscopic myomectomy? J Minim Invasive Gynecol 2008; 15:292-300.

$\checkmark 9$ Chen SY, Huang SC, Sheu BC, Chang DY, Chou LY, Hsu WC, Chang WC: Simultaneous enucleation and in situ morcellation of myomas in laparoscopic myomectomy. Taiwan J Obstet Gynecol 2010;49:279-284. 